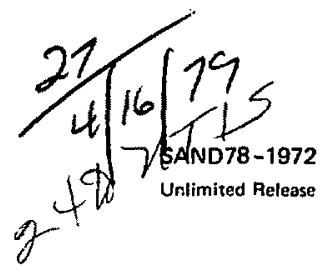

\title{
Data Acquisition and Test System Software
}

Nick A. Bourgeois, Jr. 


\section{SAND 78-1972}

Unlimited Release

Printed March 1979

IATA ACQUISITION AND TEST SYSTEM SOFTWAKE

Nick A. Bourgeois, Jr.

Advanced Systems Development Livision 1736

Sandia Laboratories

Albuquerque, NM 87185

\section{ABSTRACT}

A number of programs have been written for the Data Acquisition and Test System (DATS). These include both real time signal processing algorithms as well as data acquisition programs. 
This document is issued by Sandia Laboratories, operated for the United States Department of Energy by Sandis Corporation.

\section{NOTICE}

This document was sponsored by the United States government. Neicher the United States government nor the United States Department of Energy, nor any of their employees, nor any of their contractors, subcontractor?, or their employees makes any warranty, express or implied, or assimes any legal liability or responsibility for the accurscy, completeness or usefulness of any information, apparatus, product or process disclosed, or represents that its use would not infringe privately owned rights.

This work was sponsored and funded by:

Base and Installation Security Systems Program office Elect :onic Systems Division

Air Force Systems Cormand

Hanscom Air Force Bane, MA 01731

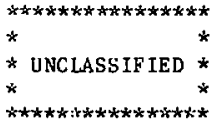


DATA ACQUISITION AND TEST SYSTEM SOFTWARE

INTRODUCTION

Sandia Laboratories has been assigned the cask by the Baso end Installation Security Syotems (BISS) Progran office to develop various aspects of perimeter security systems. One part of this effort involves the development of advanced signal procesaing techniques to reduce the. false and nuisance alarms from sensor systems while improving the probsbility of intrusion detection. Hence, the need existed for both data acquisition hardware and software. Also, the hardware is used to implement and test the signal processing algorithms $1-6$ in real time.

The hardware developed for this signal processing task is the Data Ac quisition and Test System (DATS). 7 Descriptions of the programs dieveloped for use on LATS appear in the following pages. The descriptions are taken directly from the docunentation included within the source programs themselves.

The RT-11 V02C floppy disk monitor and handler as obtained from Digital Equipment Corporation (DEC) ${ }^{*}$ has been modified to increase the max imum data rate. 9

DXMNSJ/DX: 24-Sector Floppy Disk Operating System

The original data acquisition prograns are written party in FORTRAN and partly in assembly language.

*DEC is a registered tradenark of Digital Equipment corparation, Maynard, MA 0174 . 
These two data recording programs are written entirely in assembly language. They may be triggered eitier manually or autumatically. The dual chanm r transient recorder makes more efficient use of the data disk than the dual ihannel sampler.

TROSMP.MAC: Single Channel Transient Recorder TRISMP.MAC: Dual Channel Transient Recurder

The playback prugrams may be used to deliver previously recorded data to another processor. Also, the single channel program is useful for visual display of such data.

\author{
BSDOUT.MAC: Data Playback Program \\ DBSDOT.MAC: Dual Channel Data Playback Program
}

The rol time adaptive algorithms contain many bells and whist les which may be enabled at assembly time. Diagnostic code and $f$ ile inpur/sutput are among these additional featurea incorporated as cunditional asqembly code.

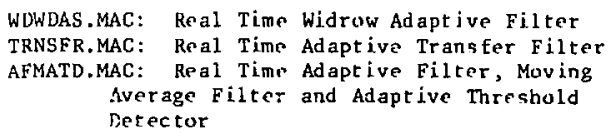

Dual channel iñput signal and internal status data of the Sensor Signal Processor Development Unit (SSPDU II) ${ }^{9}$ are recorded in transient recorder mode either when SSPDU II detects an alarm or on manual command.

$$
\text { SPDUVL,MAC: Real time SSPDU II Monitor }
$$




\section{DXMNS $J / D X$ \\ 24-Sector Floppy Disk Operating Systea: 8}

A requirement existed to do real time data acquisition at a sample rate of $1024 \mathrm{~Hz}$. The standard RT-11 floppy disk handler, DX.SYS, was unable to keep abreast af this data rate. It required about 7.5 seconds to transfer 2 seconds of data from memory to disk. The data transfer between the disk and memory occurs in two ateps, a memory-controller transaction and a controller-disk transaction. When using the LSI-11 10 computer the memory-controller transaction takes about twice as much time as the controller-disk transaction. Therefore, only one memory-disk transfer can be achieved during a single rotation of the disk. The modifications deacribed here allow up to six memory-disk transfers per disk revolution.

Certain components of the tloppy disk software within the $R$ r -11 optrating system have been modified to permit a real time thru-put in excess of $1024 \mathrm{~Hz}$. This was accomplished by changing the secior interleave, track skew and sectors per track parameters.

In standard RT-11 configuration a 2:1 sector interleave is used on a single track, a 6-sector skew is used across tracks and each track contains 26 sectors. The modifications change these parameters to $4: 1$ interleave, 8 -sector skew and 24 sectora per track. This reduces the capacity of the disk by about 8 percent.

In order to implement the 24-aector floppy disk software, an RI-1l operating system must haye an RXOl as an auxiliary device and a system device such as an RKO5. A copy of the modified handler is installed on this host machine via PATCK. The modified hander is then used to build floppy disk copies which are bootable on an LSI-11 machine. 
The following RT-11 modules have been modified and renaned as shown. All modifications requite the definition of a conditional assembly switch.

$\begin{array}{ll}\text { DXSYS.MAC } & \text { D4SYS.MAC } \\ \text { BSTRAP.MAC } & \text { B4STRP.MAC } \\ \text { RMON.MAC } & \text { K4MON.MAC } \\ \text { RMONSJ.MAC } & \text { R4HNSJ.MAC } \\ \text { DX.MAC } & \text { D4.MAC }\end{array}$

The D4SYS.MAC module contains the conditional switch definitions used by the MACRO assembler to select the code for the floppy disk and the 24-sector modifications contained in the other modules.

The B4STRP.MAC module is the software boctstrap program. The hardware boot reads the first part of the software boot from block 0 sector I of the disk. The noftware bootstrap program has been modified to continue reading itself into memory from absolute sectors 5, 9, and 13 (block 0 , logical sectors 2, 3, and 4). Reading then continues using a subrout ine which has been modified for 4:1 sector interleave, B-sector skew and 24 seccors per track.

KLMON.MAC is the keyboard monitor. The 'HSIZE' IACRO call has been modified to reflect the change in the size of the floppy handler, D4.MAC.

R4MUSJ.MAC is the resident monitor module. The 'DEVICE' MACRO call has been noditied to reflect the reduced size of the disk.

The D4.MAC module is the Eloppy disk handler. The read/write rontine has been modified for 4:1 sector interleave, 8-sector skew and 24 sectors per track.

Details of these modifications are flagged in all source files. Batch streams are available to control the assembly and linking operations. Batch streams are al so available to control the building of operating systems for BASIC, FORTRAN, and MACRO. 
DATS 1. FOR/ADAC 1. MAC

Single Channel Sampler

The program consists of the collawing modules:

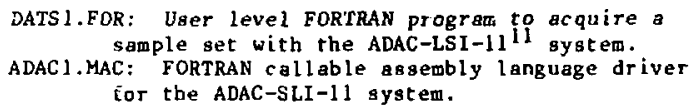

\section{DATS 1.FOR}

This program will operate DATS 7 under $24-$ sector RT-118 to obtain single channel data at a maximum sample rate of $1024 \mathrm{~Hz}$. After

ident ifying itself the program states the maximum sample rate and the data record size. One data record consists of 2048 samples. It then asks the operatur to enter the required number of data records, the name for the data file and the ADAC gain. The operator is then asked to command the start of sampling. The program so indicates, when sampling is done. A number of diagnostic messages are available for output should the need arise. An empty dish can hold a maximum of 55 data records. This corresponds to the following data window times:

$\begin{array}{ll}\text { Sample Rate } & \text { Data Window } \\ \text { Hz } & \text { MIN:SEC } \\ 1024 & 1: 50 \\ 512 & 3: 40 \\ 256 & 7: 20 \\ 128 & 14: 40\end{array}$

ADAC 1. MAC

This routine otarts the ADAC clccked sampling and interrupt driven jata transfers. It al so writes the data to the file in double buffered fashion while maintaining sampling activity. The colling sequence is as follows: 
CALL ADACDR (NSKPLS, IDATA, IWORD, ICHAN)

$\begin{array}{ll}\text { Where NSMPLS } & \text { number of records to be taken } \\ \text { IDATA } & \text { name of the data array } \\ \text { IWORD } & \text { dat record gize } \\ \text { ICHAN } & \text { output channel number }\end{array}$




\section{DATS 2. FOR / ADAC 2. MAC}

Dual Channel Sampler

The program consists of the folling modules:

DATS2.FOR: User level FORTRAN program to acquire two sample sets with the ADAC-LSI-1111 system.

ADAC 2.MAC: FORTRAN callable essembly language driver for the ADAC-SLI-11 system.

\section{DATS 2, FOR}

This program will operate DATs7 under 24-sector RT-118 to obtain dual channel data at a maximu sample rate of $512 \mathrm{~Hz}$. After identifying itself, the program states the maximum sample rate and the data record size. One dita record consista of 2048 samples. It then asks the operator to enter the required number of data records per channel, the names for the data $f i l e s$ and the ADAC gain. The operator is then asked to command the start of sampling. The data is firgt recorded and packed into a single temporary file. The program indicates when sampling is done. Then the dara is unpacked and put into separate permanent flles. A number of diagnost ic mossages are available for output should the need arise. An empty disk can hold a maximum of thirteen data records per channel. This corresponds to the following data window times:

$\begin{array}{ll}\text { Sample Rate } & \text { Da: a Window } \\ \text { Hz } & \text { MIN:SEC } \\ 512 & 0: 52 \\ 256 & 1: 44 \\ 128 & 3: 28\end{array}$

ADAC2.MAC

This rout ine starts the ADAC clocked sampling and interrupt driveri lata transfers. It also writes the data to the temporary file in double buffered fasizion while maintaining sampling activity. The calling sequence is as follows: 
CALL ADACDR (NSMPLS, IDATA, INORD, ICHANT)

\begin{tabular}{|c|c|c|}
\hline Where & $\begin{array}{l}\text { NSMPLS } \\
\text { IDATA } \\
\text { IWORD } \\
\text { ICHANT }\end{array}$ & $\begin{array}{l}\text { number of records to be taken } \\
\text { name of the data array } \\
\text { data record size } \\
\text { output channel number }\end{array}$ \\
\hline
\end{tabular}


This program is used to acquire single channel dota both preceding and following a trigger event using the Data Acquisition and Test Systro, Mode1 ? (DATS2). 7 The systen consists of a Digital Equipment Corporation (DEC) Mude1 PDP-11/03 or LSI-11 computer system 10 wich $20 \mathrm{~K}$ words of semicunductor memory, dual floppy diska, a parallel I/O card, a Texas Instruments Incurporated (TI) Model 745 portable teminal, 12 and an ADAC Gorporation Model 600-LSI-11 data acquisition and control system.11 The ADAC devico contains an analog-to-digital converter (ADC) and a pair of digital-to-analog converters (DAC). The sampled data may be displayed on any convenient $X-Y$ display monitor. 13

Data may be acquired at any of six selectable sample rates from $32 \mathrm{~Hz}$ to $1024 \mathrm{~Hz}$. This progr th executes under DEC's RT-11 operating system as modified to use 24 secturs per track 8 on the floppy disk. The program will uperate satisfactorily at or below a $256 \mathrm{~Hz}$ sample rate under the standard (26-sector) RT-11 operating system. ${ }^{14}$ An empty 24 -sector disk can hold a maximtin of 55 data records.

Data are taken in a transient recorder (TR) mode of operztion. At least one record of data is always recorded prior to the triggering event. Both the trigger and the sampling are interrupt driver. Data transfers to the disk are double buffered in data records of "RCDLEN" Iength. The value of "RCDLEN" is given in the assignments section of the source program.

The output file name and longth are entercd from the teminal keyboard following suitable prompting messages. The gain for the ADAC is al so entered in this fashion. The trigger event is announced with a message a.9 is the end of sampling. Numerous exror megsages are also available should the need arise. 
It is possible to reexecute the program without repeating the lengthy initial ID and general user information messages. The restart command syntax is different for the single job and the foreground/background monitors and is as follows:

SJ START 1000

FB REENTER 


\section{TRISHP.HAC \\ Dual Channel Transient Recorder}

This program is used to acquire dual channel data both preceding and following a trigger event using the Data Acquisicion and Test System, Model 2 (DATS2), 7 The system consists of a Digital Equipment corporation (DEC) Model PDP-11/03 or LSI-11 computer system 10 with $20 \mathrm{~K}$ words of semiconductur memory, dual floppy disks, a parallel I/0 card, a Texas Instruments Incorporated (TI) Model 745 portable terminal, 12 and an ADAC Corporation Model 600-LSI-11 data acquisition and contral system.11 The ADAC device contains an analog-to-digital converter (ADC) and a pair of digital-tomanalog converters (DAC). The sampled deta may be displayed on any convenient $X-Y$ display monitor. 13

Data may be acquired at any $r$ six selectable sample rates from $16 \mathrm{~Hz}$ io $512 \mathrm{~Hz}$. This program executeg under DEC's RT-11 aperating system as modified to use 24 sectors per track ${ }^{8}$ on the floppy disk. The progran will operate satigfactorily at or below a $128 \mathrm{~Hz}$ sample rate under the standard (26-sector) RT-11 operating system. ${ }^{14}$ An empty 24-sector disk can hold a maximum of 27 data records.

Data are taken in a transient recorder (TR) mode of operation. At least one record of data is always recorded for each channel prior to the triggering event. Both the trigger and the sampling are interrupt driven. Data transfers to the disk are double buffered in data records of "RCDIEN" length. The value of "RCDLEN" is given in the assignments section of the source progran.

The output file names and lengths are entered from the terminal keyboard following suitable prompting messages. The gain for the ADAC is also entered in this fashion. The trigger event is announced wit a message as is the end of sampling. Numerous error messages are al so available should the need arise. 
It is ровнible to reexecute the srs initial 10 and general user information messages. The restart command syntax is different for the single job and the foreground/background monirors and in as follown:

SJ START 1000

FB REENTER 
This program reads BISS data files and outputs the data in real time to a digital-to-analog converter (DAC) used as the $\mathrm{Y}$-axis. A second DAC uscd as the $x$-axis is al so driven. Buth DAC outputs range frou $+10 \mathrm{~V}$ to 10V. The DAC outputs are displayed and are al so available for external use.

BISS data files consist of an integer number of data records. Each data record contains 2048 data points or samples. Each sample is in 12-bit two's complement form.

Prompting messages guide the operator in making the several keyboard entics. The operator firgt enters the input file specification. Operator selectable gains of $1,2,4$, or 8 are available with one being the default value. The operator then chooses 256,512 , or 1324 points per frame with a default of 1024 points per frame. The choice of continuous output or pausirg at the end of each frame is available. Continuous real time output is the default. A panel switch on the data acquisition and test syster (DATS) allows the choice of plot rates. 7 The available rates are 32,64 , $128,256,512$, or 1024 points per second. The two highest plot iates require the use of the modified 24-sector monitor and handler. 8 Execution of the program may be aborted by issuing two control-c's.

The program is designed to execute under the RT-11 operating system on a Digital Equipment Corporation (DEC) Model PDP-11/03 (USI-11) computer $10,14,1516,17.15-17$ The two DAC's are part of an ADAC Corporation Hodel 600-LSI-11 data acquisition and control system. 11 The output is displayed on a Tektronix Incorporated Model 603 storage display monitor. 13

The following is typical of the terminal input/autput when executing this program. The operator's teminal input is underlined. 
R BSDOUT

BSDOUT: BISS DATA OUT

VERSION $78 \mathrm{G} 10 \mathrm{~A}$

ENTER THE INPUT FILE NAME IN THE FOLLOHING FORM:

<LEV:FILNAM.EXT

*<DX1: 7F $12 \mathrm{C} 4$

ENTER THE GAIN: i, 2, 4, OR 8

$\star$

ENTER THE POINTS PER FRAME: 256, 512, OR 1024

*

ENTER CONTINUOUS OR PAUSE: C OR P *P

PRESS RETURN TO PROCEED

PRESS RETURN TO PROCEED

PRESS RETURN TO PROCEED

PRESS RETLRN TO PROCEED

BSDOUT: END OF DATA REACHED 


\section{DBSDOT MAC \\ Dual Channel BISS Data Playback}

This prugram reads BISS data files and autputs the data in real timp to a pair of digital-to-analog cunverters (DAC). Both DAC outputa range from + $10 \mathrm{~V}$ to -10V. The DAC outputs are available for external use.

Blss data files consist of an integer number of data records. Each data record contains 2046 data points or somples. Each sample is in 12-bit two's cumplement form.

Prompting messages guide the operator in making the several keyboard entries. The uperator first enters the input file specification. Operatur selectable gains of $1,2,4$, or 8 are available with one being the defaut value. A panel switch on the Data Acquisition and Test 5ystem (DATS) allows the choice of plot rates. ${ }^{7}$ The available rates are $32,64,128$, 256, 512 , or 1024 points per second. The three highest plot rates require the use of the modified 24 -sector monitor and handler. 8 Execution of the program may be aburted by issuing two Contrul-c's.

The program is designed to exceute under the RT-11 operating system on a Digital Equipment Corporation (DEC) Model PDP-11/03 (LSI-11) computer $10,14,1516,17$. The two DAC's are part of an ADAC Corporation Mode1 600LSI-1l data acquisition and control system. 11

Thn following is typical of the terminal inpur/output when executing this program. The opertur's teminal input is underlined. The default gain is enclosed in brackets. 
R BDSDUT

DBSDOT: DUAL CHANNEL BISS DATA FLAYBACK

VERSION 78G31A

ENTER THE INPUT FILE NAMES IN THE FOLLOWING FORM:

<DF.V:F I LNAM.EXT, DEV:F ILNAM.EXT

*DXI:7K12C4,7KI2C5

ENTER THE GAIN: 102,4 , OR 8 *

DBSDOT: END OF DATA REACHED 
This program functions as in real time nonrecursive adaptive Widrow filter followed by an averaging detecter. ${ }^{18}$ The algorithm impletuented is deucribed by the following equationa and diagram 1 .

$$
\begin{aligned}
& L-1 \\
& \left.E(m)=16 *(\mid 1 / L] * \operatorname{sim}_{i=0}^{L a t} i \text { an }[0(m-i)]\right) * 2 \\
& o(m)=b(n)-H(n) \\
& \text { K } \\
& H(m)=\text { S:mation }[B(n, m) * S(m-3-n)] \\
& \pi=1 \\
& B(n, m+1)=Q *[B(n, m)+[V * 0(m) * S(m-J-n)]] \\
& \text { where } B(n, w) \text { dynamic filter coefficients } \\
& E(m) \text { outputs from the detector } \\
& O(a) \text { outputs from the filter } \\
& S(m) \text { signal input samples } \\
& J \text { number of signal time delays } \\
& K \text { number of filter sections } \\
& \text { L number of detector elements } \\
& \text { n sample number } \\
& \text { n filter coefficient number } \\
& \text { Q Ahmed-Jackı in coefficient } \\
& \mathrm{V} \text { control coefficient }
\end{aligned}
$$

All mathematic operations are performed in fixed poirt arithmetic uging the excended instruction set (EIS) integer instructions. ${ }^{10}$ In the following tabulation the binary point is located to the left of the most significant " $l$ " or to the left of the " $v$." The "l " $\mathrm{s}$ " indicate significant information to the right of the binary point. The " $m$ 's" indicate possible significant information to the left of the binary point. The " 0 's" indicate the absence of significant information. The " $y$ " indicates a virtual digit that carries no significant information. The sign bit is indicated by an " $s$." The " $\mathrm{p}$ " $\mathrm{s}$ " and " $\mathrm{q}$ ' $s$ " represent the number of bits to the left and to the right of the binary point, respectively. 


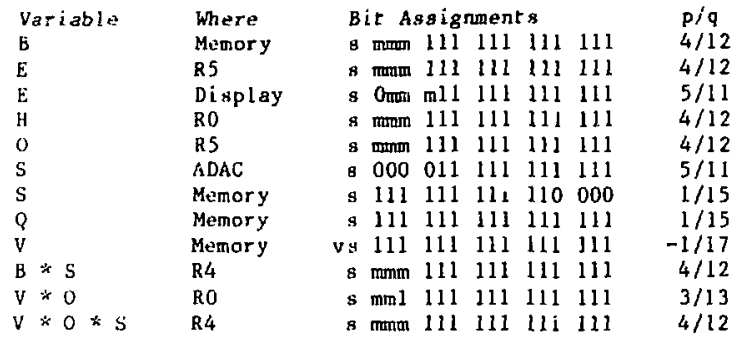

When executing on a Digital Equipment Corporation (DEC) Model PDP$11 / 03$ (LSI-11) computer c $^{10}$ the sample rate with this program is 128 samples per second. The input samples are obtained from an ADAC Sorporation Model 600-LSI-11 data acquisition and control system. 11 The ADAC device contains a 12-bit analog-to-digital converter ana a pair of 12-bit digital-toanalog converters. The output of the detector is displayed on a Tekt ranix Incorporated Model 603 storage display monitorl3 at 4096 points per frame. An antiailasing filter should precede the analog-to-digital converter. The filter characteristics should be as follows:

$40 \mathrm{~Hz}$ sutoff frequency

$12 \mathrm{db}$ per octave rolloff.

The filter coefficeients must be modified by the "Q" coefficient to prevent the adaptive filter from adapting to the low level quantization noise that is always present on the inpist.

The following paragraphs describe the effects of using the several conditional code sets contained in this program. The name of each of the conditional assembly switches appears at the beginning of each paragraph. 
DIAG. The output display is changed to 1024 points per frame.

Diagnostic code is inserted co count the number of input aignal samples, to detect and count overflows and to add threshold detectors and counters for all inputs and outpurs. Also, code estall $i$ shing the number of point per Erame is modified to make this value variable via PATCH or ODT. A 100word block of wemory is reserved for parching.

FAKE. The real time read routine is replaced to permit operation from data stored in memory.

FILE. The real time read routine is replered to permit input from a file and output to a file. The signal and output file names are entered from the console keyboard during initializing.

RCRD. Code is added to rcord both the input to the filter and the output from the averaging detector. The file names are entered from the console keyboard during initialization. Minimum ano naximu file lengths are as follows:

$\begin{array}{llll}\text { Memory } & \text { Records } & \text { Blocks } & \text { Time } \\ 12 \mathrm{~K} & 1 & 8 & 16 \text { Aeconds } \\ 16 \mathrm{~K} & 2 & 16 & 32 \text { seconds } \\ 20 \mathrm{~K} & 3 & 24 & 48 \text { reconds } \\ 24 \mathrm{~K} & 4 & 32 & 64 \text { seconds } \\ 28 \mathrm{~K} & 5 & 40 & 80 \text { seconds }\end{array}$

NSCP. Code addressing the display registers is disabled t. permit execution on the $P D P-11 / 34$ which has no such device.

TIME. An instruction to clear the $X$-axis $D A C$ is issued at the end of each pertinent module for execution time measuring purposes. This instruciton is also issued twice at the end of each pass through the progran *

skVs. The code is wodified to rm in a memory only machine with no RT11 operating system and no cerminal. 
WGHT, Code is added to record the filter weights or coefficients following the processing of each 64th sample. If the file space required excerds the capacity of the floppy disk also use the conditional "NDSP=1." This will permit execution on the PDP-11/34 with its larger disks. When, using this "WCHT=1" conditional the number of filter sactions nust not exceed 64. This is specified when using the couditional "CNFG=1" with the lab:: 1 "SECTNS". The "TIME= $l$ " conditional may not be used if both the "WCHT $=1$ " and the "NDSP=1" condit tonala are ured.

JSSE. The adaptive filter requires the input of an impulse function once each " $2 * K$ " samples to prevent it from adapting to the low level quantization noise that is always present on the input. This is in lieu of the " $Q$ " coefficient.

PRTM. Cude is included to canse the time of day to be printed on the console terminal for each alarm that is detected. The date is also printed with the first detected alara following a midnight rollover. 


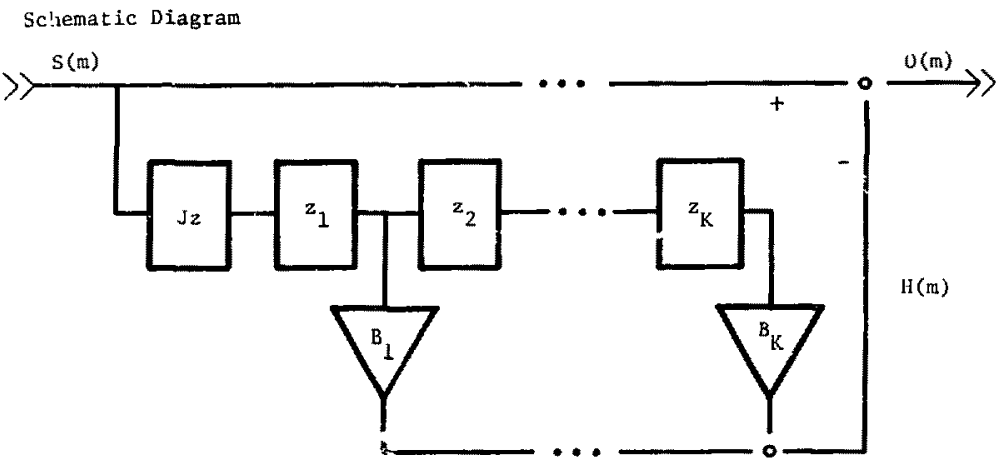

Diagram 1 


\section{Real Time Adaptive Trangfer Filter}

This program functions as a real time nonrecursive adaptive transfer filter. 3 The filter veights for the signal filter are copied from those of the reference filte: The algorithm implemented is described by the tollowing equations and diagram 2.

$$
\begin{aligned}
& O(m)=S(m-C)-H(m) \\
& \mathrm{K} \\
& H(m)=\text { Summation }[B(n, m) * 3(m-C-J-n)\} \\
& n=1 \\
& B(\pi, m+1)=B(n, m)+[V * E(m) * R(\pi-D-I-n)] \\
& E(m)=R(m-D)-G(m) \\
& \mathrm{k} \\
& G(m)=\text { Sumation }[B(n, m) * R(m-D-I-n)] \\
& \mathrm{n}=1 \\
& \text { where } B(n, m) \text { dynamic filter coefficients } \\
& E(m) \text { outputs frow the predicter } \\
& O(m) \text { outputs from the filter } \\
& R(m) \text { reference input samples } \\
& S(\mathrm{~m}) \text { signal input samples } \\
& \text { C nuber of signal time delays } \\
& \text { outside the filter locp } \\
& \text { D number of reference } t \text { ime delays } \\
& \text { outside the filter loop } \\
& \text { I number of reference time delays } \\
& \text { inside the filter loop } \\
& \text { l.umber of signal time delays } \\
& \text { inside the filter loop } \\
& \text { number of filter sections } \\
& \text { samile number } \\
& \text { filter coefficient number } \\
& \text { control coefficient }
\end{aligned}
$$

All mathemat ic operations are performed in fixed point arithmet ic using the extended instruction set (EIS) integer instructions. 10 In the following $t$ abulation the binary point is located to the left of the most

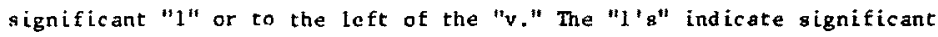
information to the right of the binary point. The "m's" indicate 
significant information to the left of the biary point. The " 0 ' 8 " indicate the absence of significant information. The " $v^{*}$ indicates a virtual digit that carries no significant information. The sign bit is indicated by an " $s$." The " $p$ ' $s$ " and " $q$ 's" represent the number of birs to the left and to the right of the binary point, respectively.

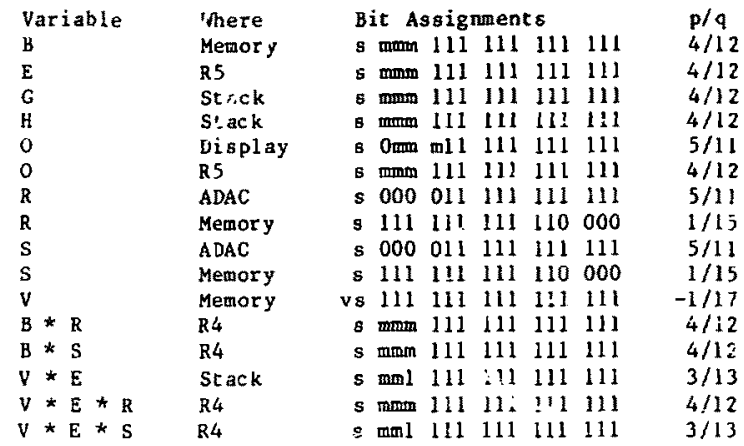

When executing on a Digital Equipment Corporation (DEC) Model PDF$11 / 03^{*}$ (LSI-11) computer ${ }^{10}$ the sample rate with this program is 128 samples per second. Since samples are taken on alternate clock pulses for the signal and the reference inputs, the clock must be set to $r$ un at twice the sample rate. The input samples are obtained from an ADAC Corporation Model 600-LSI-11 data acquisition and control system. 11 The signal is on channel one and the reference is on chanel two. The ADAC device contains a 12-bit analog-to-digital converter and a pair of 12-bit digital-toanalog converters. The output of the filter is displayed on a Tektronix Incorporated Model 603 storage display monitor 13 at $4 \mathrm{C} 96$ points per frane.

The following paragraphs describe the effects of using the several conditional code sets contained in this progran. The name of each of the conditional assembly switches appears at the beginning of each paragraph. 
DLAG. Diagnostic code is inserted to rount the number of input signal samples, to detect and count overflows, and to add threshold detectors and councers for all inputs and outputs. Also, code establishing the display magnitude and the number of points per frame is modified to make this values variable via PATCH or ODT. A 100-word block of memory is reserved for patching. The sample rate muat be reduced below $128 \mathrm{~Hz}$.

FAXE. The real time read routines are replaced to permit operation from data stored in memory. Separate vuffers of data are supplied for the signal and the reference.

FILE. The real time read routines are replaced to permit input from files and output to a file. The signal, reference and output file names are entered from the console keyboard during initialization. The output display is changed to 1024 points per frame. 
Sctlemat:c Diagran
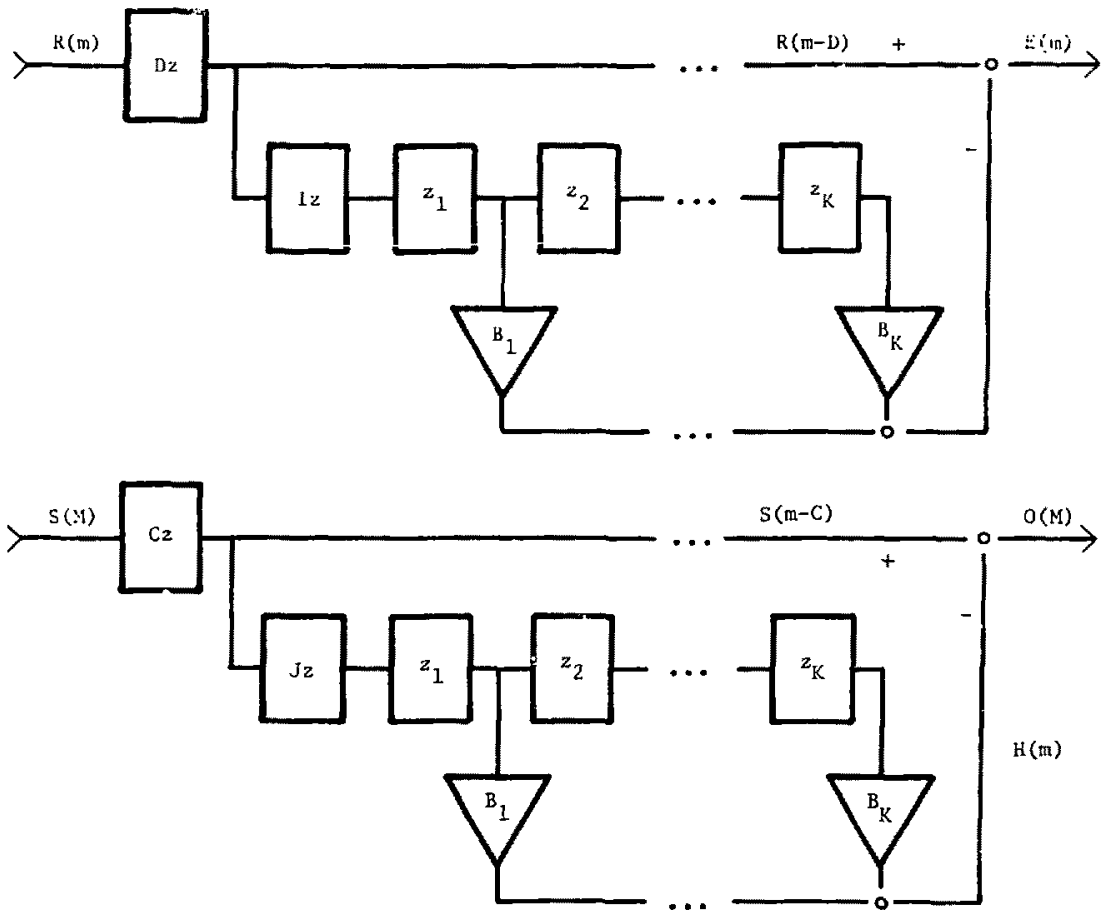

Diagram 2 


\section{AFMATD . MAC \\ Real lime Adaptive Filter, Muving Average Filter and Adaptive Threshold Detector}

This program functions as a real time nonrecursive adaptive filter (ADF) followed by a moving sverage tilter (MAF) and an adaptive threshold detector (ATD) 1,2 The algorithm implemented is deacribed by the following expressions and by diagrams $3,4,5$ and 6 .

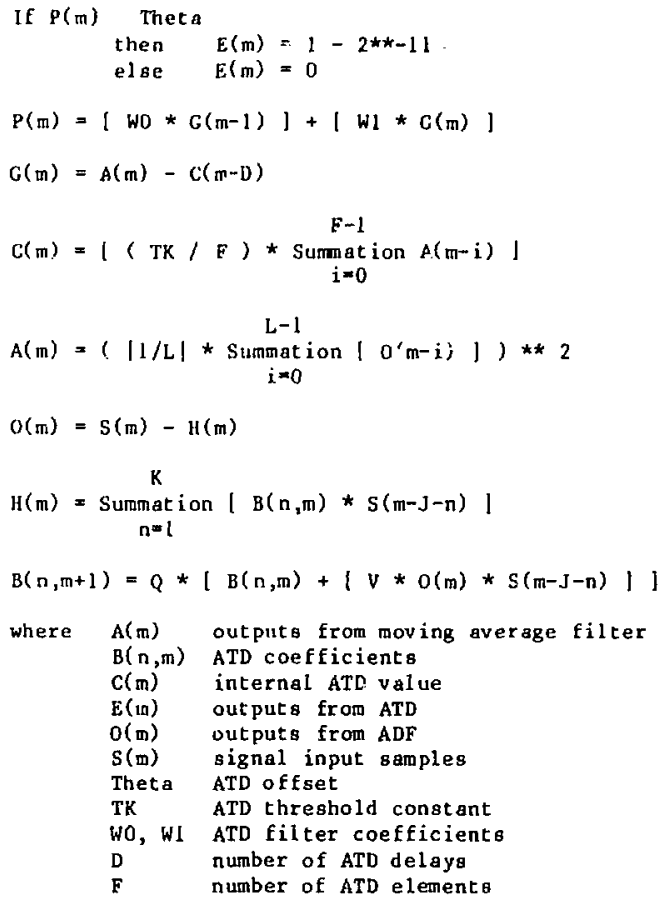




$\begin{array}{ll}J & \text { number of ADF delays } \\ K & \text { number of ADF sections } \\ \mathrm{L} & \text { number of MAF and ATD elements } \\ \mathrm{m} & \text { sample number } \\ \mathrm{n} & \text { ADF coefficient number } \\ Q & \text { Ahmed-Jacklin coefficient } \\ V & \text { ADF feedback control coefficient }\end{array}$

All mathematic operations are ferformed in fixed point arithmetic using the extended instruction set (EIS) integer instructions.10 In the following tabulation the binary point is located to the left of the most significant " $l$ " or to the left of the " $y$." The "l' $s$ " indicate significant information to the right of the binary point. The "m's" indicate possibl. significant information to the left of the binary point. The " 0 's" indicate the absence of significant information. The " $v$ " indicates a virtual digit that carries no significant information. The sign bit is indicated by an "s." The " $p$ ' $s$ " and " $q$ ' $s$ " represent the number of bits to the left and to the right of the binary point, respectively.18

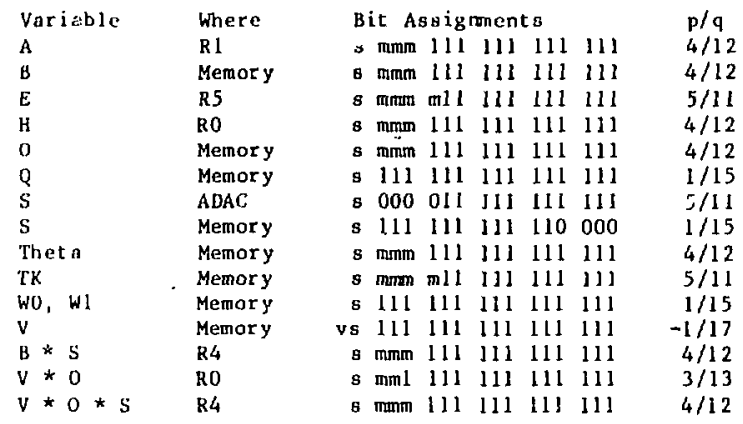

The " $p$ 's" and " $q$ ' $s$ " resulting from the arithmetic instructions in this program are as shown below. For all operations:

$$
p+q=p 1+q 1=p 2+q 2=16
$$


Addition and Subtraction

$$
\begin{aligned}
& p=F_{1}=p^{2} \\
& q=q_{1}=q^{2}
\end{aligned}
$$

Multiplication

$$
\begin{aligned}
& p=p 1+p 2 \\
& q=q 1=q 2-16
\end{aligned}
$$

Division

$$
\begin{aligned}
& p=p 1-p 2 \\
& q=q 1-q 2+16 .
\end{aligned}
$$

When executing on a Digital Equipment Corporation (DEC) Model PDP$11 / 03^{*}$ (LSI-11) computer $10,15,17$ the sample rate with this program is 128 samples per second. The input samples are obtained from an ADAC Corporation Model 600-LSI-11 data acquisition and control system. 11 The ADAC device contains a 12-bit analog-to-digital converter and a pair of 12bit digital-to-analog converters. The input signal and the outputs of the ADF, MAF, and ATD are displayed on a Tektronix Incorporated Model 603 storage display monitor ${ }^{13}$ at 1024 points per trace. An antialiasing filter should precede the analog-to-digital converter. The filter characteristics should be as follows:

$40 \mathrm{~Hz}$ cutoff frequency

$12 \mathrm{db}$ per octave rolloff.

The following paragraphs describe the effects of using the several conditional code sets contained in this program. The name of each of the conditional assembly switches apfears at the beginning of each paragraph.

DIAG. Diagnostic code is inserted to count the number of input aignal samples and to detect and count overflows. A 100-word block of memory is reserved for iatching. 
DlAG. Diagnostic code is inserted to count the number of input signal sampliss and to detect and count overflows. A 100-word block of memory is ruserved for patching.

FAKE. The real time read routine is replaced to permit operation from data siorted in memory.

FILE. The real time read rout ine is replaced to permit input trom a fila and output to a file. The signal and output file names are entered from the console keyboard during initial izing.

RCRD, Code is added to rcord both the input to the filter and the sutput from the averaging detector. The file names are entered from the console keyboard during initialization. Minimum and maximum file lengths art as follows:

$\begin{array}{rrrrl}\text { Memory } & \text { Records } & \text { Blacks } & \text { Time } & \\ \text { 12K } & 1 & 8 & 16 \text { seconds } \\ 16 \mathrm{~K} & 2 & 16 & 32 \text { seconds } \\ 20 \mathrm{~K} & 3 & 24 & 48 \text { seconds } \\ 24 \mathrm{~K} & 4 & 32 & 64 \text { second s } \\ 28 \mathrm{~K} & 5 & 40 & 80 \text { seconds }\end{array}$

NDSP. Code addressing the display registers is disabled to permit execution on the PDP-11/34 which has no such device.

TIME. An instruction to clear the $x$-axis DAC is issued at the end of each pertinent module for execution tine measuring purposes. This instruciton is also isaued twice at the end of eact pass through the program.

SKVS. The code is modified to run in a memory only wachine with no RT11 operating system and no terminal.

WGHT. Code is added to record the filter weights or coefficients following the processing of each 64th sample. If the file space required exceeds the capacity of the floppy disk also use the conditional "NDSP=1". 
Thia will permit execution on the PDP-11/34 with its larger diskg, When using this "WGHT=l" conditional the number of filter aections must not axceed 64. This is specified then using the conditional "CNFG=1" with the label "KKKK." The "TIME-1" conditional may nat be uaed if both the "WGHT=l" and the "NDSP=1" conditionala are used.

JSSS. The adaptive filter is given an impul se function once each " $2 \star K "$ samples to prevent it from adapting to the low level quantization noise that is always present. This is in lieu of the "Q" coefficienc.

PRTM. Code is included to cause the time of day to be printed on the carsole reminal for each alarm that is detected. The date is also printed with the first detected alarm foilowing gtartup and subsequent midnight rollovers. 
Block Diagran

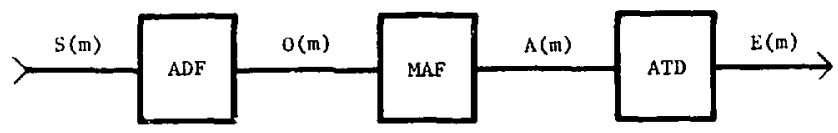

Diagrain 3

ADF Schemat ic Diagran

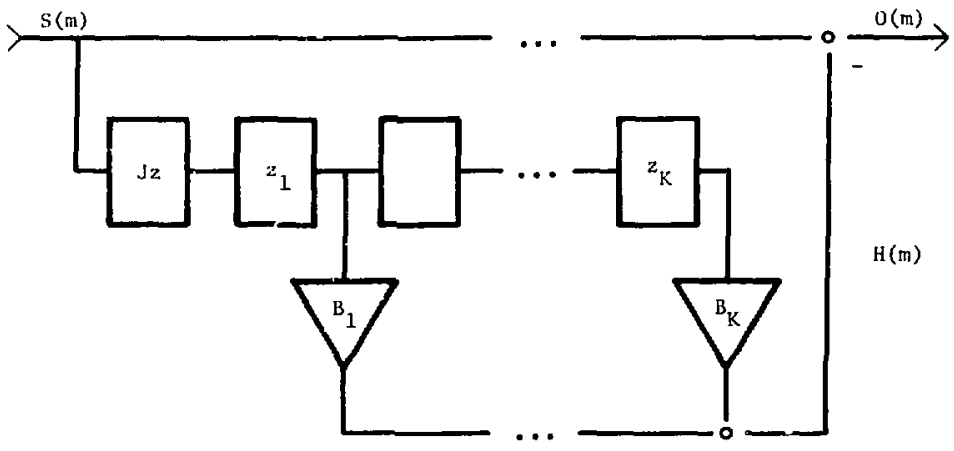

Diagram 4

MAF Schematic Diagram

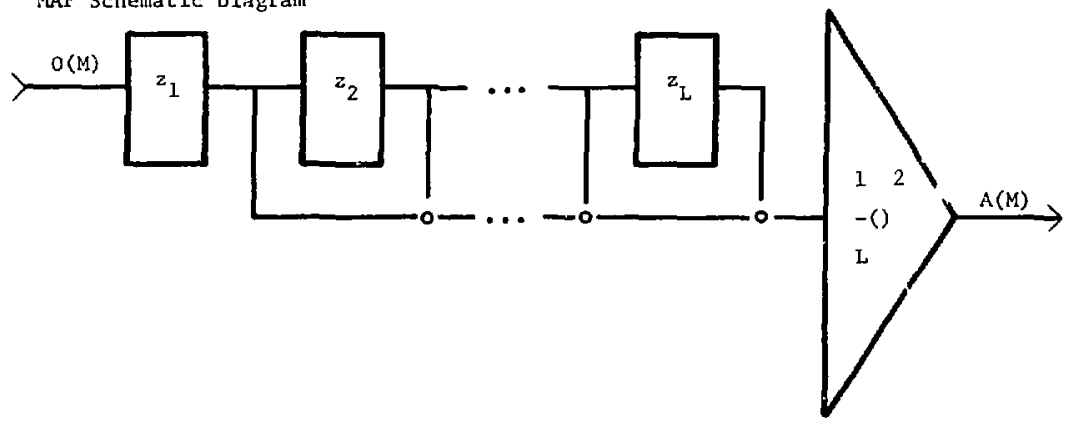

Diagram 5 
ATD Schemat Ic Diagram

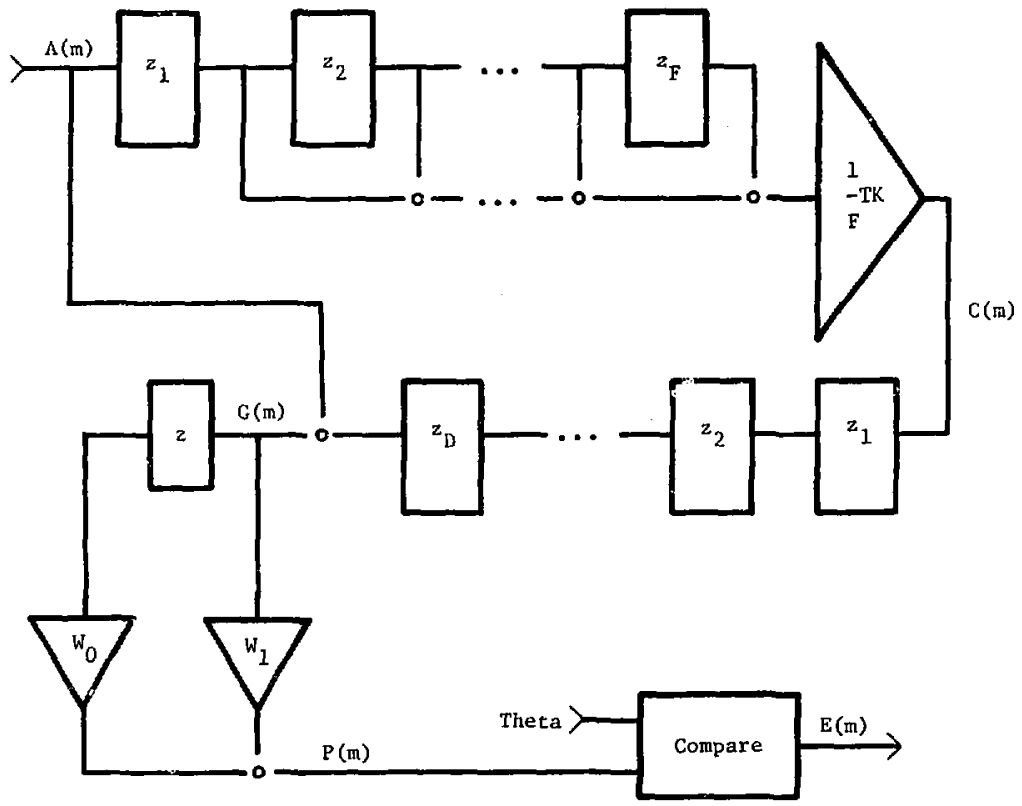

Diagram 6 


\section{. SPDUVL . MAC \\ Real Time SSPDU il Monitur}

This program is usod to record the dual channel analog signal data being processed by the Dual Channel Sensor Signal Processor Development Unit (SSPDU II) 9 using the Data Acquisition and Test System, Modt1 2 $(\operatorname{DATS} 2)^{7}$. The program al so records SSPDU II status data ither on command. from SSPDU II or from DATS2. The program is terminated after recording an operator-dettmined number of SSPDU II and/or DATS2 initiatud triggera. It may also be aborted at any time by the operator without loss of any dat a by issuing double Control-C. The sampled signal data may be displayed on any convenient $X-Y$ display monitur. 13

The program is written in Digital Equipment Corporation's (DEC) PDP11 MACRO-11 assembly language $10,15,17$ It is designed to execute under the RT-11 V03 operating system using the forground/background monitor. 14, 16

Earh recording Comrand results in the recording of one signal data record and one status data record. The channel 0 and 1 commands record signal and status data for channels 0 and 1 , respectively. The snapshot comand records signal and status data for both channels. The signal data are recorded in the standard DATS integer format. This formut consists of records of 2048 samples where each sample is a right justified 12-bit two's rmmplement integer. The signal data are recorded in transient recorder mode such that the recording command or trigger always occurs during the second half of the signal's data record. The status data are recorded in records of 256 16-bit words. The contents of the status data re given in Table I. 19 Each word of this status data is made up as follows:

$\begin{array}{ll}\text { Bits } 15-4 & \text { Data, two's complement integer } \\ \text { Bits } 3-1 & \text { not used } \\ \text { Bit } 0 & \text { Validity indicator }\end{array}$


The data are all recorded in files on floppy digks. It is not neceqsary, although degirable, to start with an initialized (empty) disk. However, the disk must be in a compressed or "Squezzd" condition. The Eilo names for the signal and status data are the game for a given channel. The file name extension for signal data is ",DAT" and for status data is ".STS." The output file names and lengths are entered from the console keyboard following suitable prompting messages. The gain for the analog-to-digital converter (ADAC) is also entered in this fashion. Triggtr events are indicated by printing the number of unrecorded records (alarms) remaining for each channel on the terminal. Program termination is identified with a messnge. Following program temination the datadisk is "SQUEEZEd" and its directory is printed on the console temrinal. Numerous etror messages are also available sould the need arise. A block diagram of the system appears in diagram 7 . 
TABLE I

Status Data

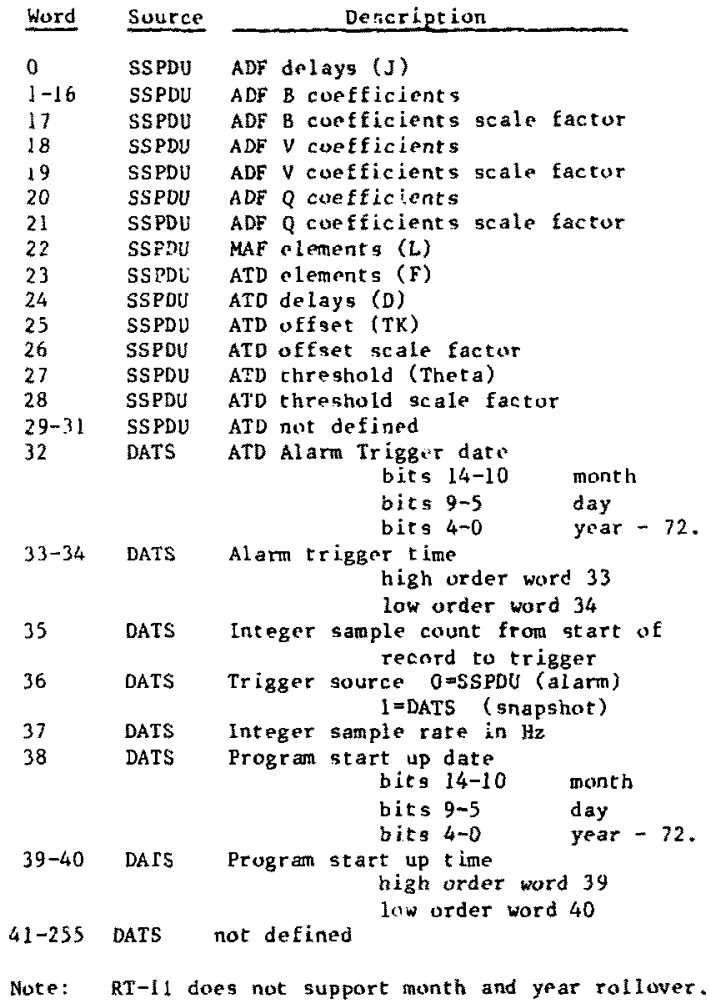




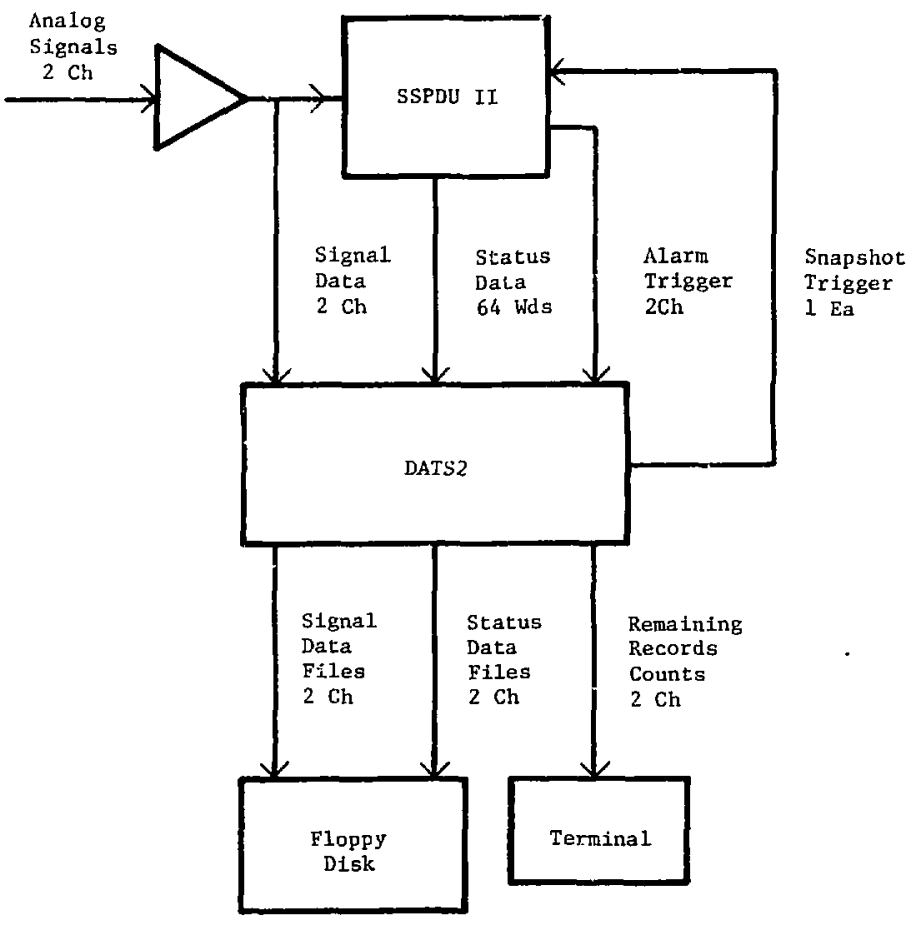

Díagram 7 
The following is typical of the terminal input/outpist when execuling this program. The operator's terminal input is underlined.

\begin{tabular}{lll}
\multicolumn{2}{r}{ S SPDUVL } \\
SPDUVL: & $\begin{array}{l}\text { SSPDU II DATA ACQU } \\
\text { VERSICN 78G06A }\end{array}$ \\
SAMPLS & CLOCK & TIME \\
RATE & RATE & WINDOW \\
Hz & Hz & MIN: SEC/RCD \\
128 & 256 & $0: 16$ \\
64 & 128 & $0: 32$ \\
32 & 64 & $1: 04$ \\
16 & 32 & $2: 06$
\end{tabular}

EACH RECORD CONTAINS 2048 SAMPLES

SET THE CLOCK AND ENTER THE SAMPLE RATE

$\star 128$

ENTER THE 1-6 CHARACTER FILE NAME FOR CHANN *8G06A0

ENTER THE 1-6 CHARACTER FILE NAME FOR CHANNEL 1 $\star 8 G 06 \mathrm{Al}$

ENTER TKE NUMBER OF ALARMS: $1,2, \ldots, 25$ OR 26 $\star \underline{3}$

ENTER THE ADAC GAIN: 1, 2, 5 OR 10

*1

DISK SPACE REMAINING

$\mathrm{CHO} / \mathrm{CH} 1$

$3 / 3$

$3 / 2$

$3 / 1$

$2 / 1$

$2 / 0$

SPDUVL: PROGRAM TERMINATING 06-Ju1-78 8G06A0. DAT 8G06A0.STS <UNUSED> 444

4 Files, 36 Blocks

444 Free Blocks 


\section{References}

1. C. R. Elliott, W. L. Jackl in, S. D. Stearna, "The Adaptive Digital Filter," SAND 76-0360, Sandia Laboratories, Albuquerque, NM 87185, Aug 76.

2. N. Ahmed, letrer to G. R. Elliot t, Kansas Stat University, Manhat tan, KA 66505, 20maug 76 .

3. G. R. Elliott, S. D. Stearns, N. Ahmed, "Adaptive Transfer Filter Considerations," Conference Record, Eleventh Asilamar Confersnce on Circuits, Systems and Computers, hov 77 .

4. N. Ahmed, "A Study of Adaptive Digital Filters," SAND77-0102, Sandia Laboratories, Albuquerque, NM 87185 , Aug 77 .

5. G. R. Elliott, "Selective Digital Filtering," SAND77-1297, Sandia Laboratories, Albuquerque, NM 87185, Nay 77 .

6. N. Ahmed, "On Intrusion-Detection Via Adaptive Prediction," SAND771591, Eandia Laboratories, Albuquerque, MM 87185, Apr 78.

7. R. P. Kromer, "A Small Portable Data Arquisition System," SAND77$1845 \mathrm{C}$, Sandia Laboratories, Albuquerque, NM 87185, DeC 77.

8. I. A. Bourgeois, Jr. "24-Sector Floppy Disk System," SAND77-0228, Sandia Laboratories, Albuquerque, NM 87185, Jan 77.

9. J. E. Simpson, "Preliminary Design Definition for the Dual Input Processar Module, Puase I," unpubl ished, Sandia Laboratories, Albuquerque, INM 87185,7 Mar 76.

10. "Microcomputer Handbook," second edition, EB 07948, Digital Equipment Corporation, Maynard, MA 01754, 1977.

11. "Instruction Manual for Data Acquisition and Control System," 600-LSI" 11. ADAC Corporation, Woburn, MA $0175 \%$.

12. "Model 745 Portable Data Terminal Operating Instructions," 9840249701, Texas Inatruments Incorporated, Houston, TX 77001, 15 Def 75.

13. "Instruction Manual, 603/604 Monitor," 070-1259-01, Tektronix Incorporated, Beaverton, OR 97005, Jul 76.

14. "Software Product Description, DEC 11 XPDAS-G-D, Digital Equipment Corporation, Maynard, MA 01754, Aug 77.

15. "PDPll MACRO-11 language Reference Manual," AA-50775A-TC, Digital Equipment Corporation, Maynard, MA 01754, Aug 77.

16. "RT-11 System User's Guide," DEC-11-ORGDA-A-D, Digital Equipment Corporation, Maynard, MA 01754, Aug 77 . 
17. "RT-11 Advanced Programer's Guide," DEC-11-ORAPA-A-D, Digital Equipment Corporation, Maynard, MA 01754, Oet 77.

18. N. A. Bourgeois, Jr. "The Software Development of a Real Time Signal Processing Sys ," SAND77-1684, Sandia Laborarories, Albuquerque, MM 87185, Dec 77 .

19. J. E. Simpson, "SSPDU II Satus Data Formats," undublished, Sandia Laborataries, Albuquerque, NM 87185, 27 Jul 78. 
DISTR IBUTION :

HEADQUARTERS ( 3 )

ESD/MCB/STOP 36

HANSCOM AFB, HA 01731

ATTN: CUL. R. T. KOZUMA, OCB

LT. COL. P. E, PECO, OCBE

B. ALLEN, OCBE

HEA DQUARTERS

ROME AIR DEVELOPMENT CENTER (AFCS)

GRIFFISS AFB, NY 13441

ATTN: R. ALLEN, OCDS

US ARMY MOBILITY EQUIPMENT RESEARCH AND DEVELOPMENT COMMAND

FT. BELVOIR, VA 22060

ATTN: D. KEEHAN, DRXFB-XS

NAVAL UNDERSEA CENTER (2)

SAN DIEGO, CA. 92132

ATTN : J. RE.DFERN

J. ZIEDLER

INSTITUIE FOR COMPUTER SCIENCES AND TECHNOLOGY

US DEPARTMENT OF COMMERCE

NATIONAL BUREAU OF STANDARDS

WASHINGTON, DC 20234

ATIN: R. T. MOORE, CHIEF

COMPUTER SYSTEMS SECTION

DEPARTMENT OF THE NAVY

NAVAL COASTAL SYSTEMS LABS

PANAMA CITY, FL 32401

ATTN: R. FORBUS

DIRECTOR

DEFENSE NUCLEAR AGENCY

WASHINGTON, DC 20305

AITN: M, BEASLEY, NSSO

KANSAS STATE UNIVERSITY

DEPARTMENT OF ELEC 4 ?CAL ENGINEERING

MANHATTAN, KS 66506

ATTN: N. AIMED

NEW MEXICO STATE UNIVERSITY

DEPARTMENT OF COMPUTER SCIENCE

LAS CRUCES, NM 88003

ATTN: D. DEARHOLT 


\begin{tabular}{|c|c|}
\hline 1000 & G. A. FOWLER \\
\hline 1111 & S. D. STEARNS (15) \\
\hline$\$ 241$ & R. N. HORTON \\
\hline 1426 & A. J. ROTH \\
\hline 1483 & D. M. MORRISON \\
\hline 1521 & J, L, MORI LEY \\
\hline 1523 & F, I. MAGEE \\
\hline 1523 & R. E. TRELlue \\
\hline 1554 & N. J. POLLARD \\
\hline 1584 & T. M. SCHULTHEIS \\
\hline 1700 & W. C. MYRE \\
\hline 1710 & V. E. BLAKE, JR. \\
\hline 1730 & C. H. MALNEY \\
\hline $1730 \mathrm{~A}$ & R. K. PE'TERSEN \\
\hline 1731 & E. R. JULIUS \\
\hline 1732 & R. F, SYLER \\
\hline 1733 & T, J. HOBAN, JR. \\
\hline 1734 & W. N. CAUDLE \\
\hline 1736 & D. C. HANSON \\
\hline 1736 & N. A. BOURGEOIS, JR. (6) \\
\hline 1736 & G. W. DONOHOE \\
\hline 1736 & G. R. ELLIOTT (15) \\
\hline 1736 & R. J. GOSSETT \\
\hline 1736 & W. L. JACKLIN \\
\hline 1736 & R. P. KROMER \\
\hline 1736 & L. W. HASCHOFF \\
\hline 1736 & J. E. SCHE IBAER \\
\hline 1736 & J. E. SIMPSON \\
\hline 1736 & R. A. WAYNE \\
\hline $1: 39$ & J. D. WILLIAMS \\
\hline 1750 & J. E. STIEGLER \\
\hline 1759 & M. J. EATON \\
\hline 1760 & J. JACOBS \\
\hline 2351 & T. C. BRYANT, JR. \\
\hline 2355 & D. H. JENSEN \\
\hline 2532 & R, A. HAYENGA \\
\hline 2534 & R. W. ROBERTS \\
\hline 2627 & R. M. JAMES \\
\hline 2648 & L. F. TOLENDINO \\
\hline 2648 & T. M. UNKELHAEUSER \\
\hline 4722 & B. STIEFELD \\
\hline 5613 & J. H. GRAHAM \\
\hline 8450 & D. N. TANNER \\
\hline 8266 & E. A. AAS \\
\hline 3141 & T. L. WERNER (5) \\
\hline 3151 & W. L. GARNER (3) \\
\hline DOE $T$ & FOR DOE/TIC (UNLIMITED RELEASE) \\
\hline
\end{tabular}

(R. F. Campbeil, 3172-3) 